\title{
LOCATING THE M(O)THER
}

\begin{abstract}
Angie Voela
In order to find oneself one must find the $\mathrm{M}(\mathrm{O})$ ther - or is it the other way round? The task is more complicated when ambivalence gets in the way; ambivalence towards the primordial object of love and all subsequent objects of love; towards the biological potential of becoming a mother or turning into one's mother as one gets older. Being part of the patriarchal symbolic order, mother speaks its values intentionally or unintentionally, transmits values, subjection or resistance, lays the foundations for discontent at being a woman. Thus, when women embark on a journey of self discovery, they inevitably cross the threshold of the $\mathrm{M}(\mathrm{O})$ ther. In some cases they do so by arriving at a place which reverberates with her presence. A pattern emerges which points at a revision of ways of being and a shift in the iconography of the maternal and the personal.

Locating the $\mathrm{M}(\mathrm{O})$ ther is always an arduous real/poetic task. I am using this hybrid term for two reasons: first, because below I will be discussing contemporary novels. The benefits of using literary texts as data in social sciences have been well documented over a number of decades (Laurenston \& Singewood 1971; Brinkmann, 2009) and the descriptive term 'midfictions' (Durante 2001, p.7), recently proposed by some scholars for literary texts with a strong sociological component, is indicative of the growing overlap between the humanities and the social sciences. Feminists have always considered literature as an integral part of both researching femininity in the past and of constructing new fabulations (Cixous cited in Barr, 1992) which actively inscribe women in the present and the future. In the analysis, below I therefore consider three Greek novels (The Magium, Filthy Weather and Eleni or Nobody) as real/poetic fabulations/midifictions, valid testimonies of the personal and the collective experience of women, even when they veer off the realistic path and offer highly symbolic (re)solutions to certain problems.

The other reason is theoretical and concerns the use of Lacanian psychoanalysis and the Foucauldian notion of heterotopia in the theoretical framework of this paper (explained in detail below). In all three novels, women embark on a journey of self discovery which has strong similarities to the analytic process and brings them to a heterotopic place. Women have long been known to resort to heterotopias, places with special properties, like the $19^{\text {th }}$ century all-female teaching college, where they were able to fashion new forms of subjectivity (Tamboukou 2000, p.261) before returning to the big
\end{abstract}


world. In Different Spaces (2000, p.180), Foucault considers heterotopias to be actual places or emplacement 'with the curious property of being connected to all other emplacements, but in such a way that they suspend, neutralise, or reverse the set of relations that are designated, reflected or represented [reflechis] by them' (2000, p.178). Hetherington considers heterotopias as places of hopeful anticipation with emphasis on process and ordering instead of order (1997, p.7). Further, these are places which juxtapose things that are normally seen as not going together (1997, p.9). Thus, what is being signified 'cannot be easily attached to a referent' (ibid). In The Order of Things (2006, p.xix) however, Foucault employs the same term to refer to the linguistic experience of transgression and going beyond representation, thus making room for a literary conception of space.

The cases I examine in this paper concern emerging contemporary heterotopias which have strong maternal characteristics. They are both actual places in which women contemplate the complexities of their maternal attachments, and literary places with which women express the shifts and changes in the maternal iconography and the representation of femininity. In the same context, by using Psychoanalysis and terms like 'symptom', 'fantasy' and 'shedding to baggage of the unconscious', I do not wish to emphasise the achievement of 'closure' or 'arrival at the end' but to draw attention to how the resignification of the mother in terms of space inaugurates a new phase in personal and collective feminine politics. 'To locate', in that sense, does not mean to pin-point or dissolve but to assign something its proper (poetic) place.

Below I proceed by giving a brief account of the three novels. Subsequently, I discuss how the Foucauldian heterotopia and Lacanian analysis converge in the realm of theory. This is illustrated with examples from the three novels and followed by a discussion-interpretation of the Greek paradigm. Beyond the local concern, however, I draw attention to the wider significance of the maternal locus, arguing that its emergence is not the accidental by-product of a specific contemporary culture but a deliberate gesture carving a space of alternative ordering, a 'critical site' with the potential of accommodating the permanent and fruitful problematisation of ordinary life.

The three novels I discuss are The Magium by Dimitra Kolliakou (1999), Filthy Weather by Amanda Michalopoulou (2001) and Eleni or Nobody by Rhea Galanaki $(1998)^{1}$. The first two are autobiographical fictions set in the present. The Magium is a 
young woman's re-examination of life after the death of her mother. The story begins a few months before the event, when Marina falls in love with the Israeli Sharon who wants to commit to a long-term relationship. Marina has her reservations. She travels to Athens frequently to visit her terminally ill mother, then moves to Holland for a postdoctoral placement, then returns to England for a while and later decides to join Sharon in Israel. As part of her attempt to come to terms with the profound changes in her life, the heroine sets out to re-discover 'the Magium' of her childhood, an imaginary locus of female omnipotence associated with the mother.

Filthy Weather highlights the fragility of human relations and the ambivalence towards the maternal. The action takes place in a small holiday island where Victoria, the heroine, arrives with her boyfriend, a successful novelist whom he admires. Key to the unfolding of events is a relatively inaccessible beach with a derelict house. Victoria becomes increasingly obsessed with the house and its former mysterious and now dead owner, 'the Frenchwoman'. The house will become the scene of sexual encounters, emotional upheavals, enlightenment and, eventually, Victoria's exile and the deciphering of the Frenchwoman's life.

Eleni or Nobody ${ }^{2}$ is the fictional biography of the $19^{\text {th }}$ century painter Eleni Boukoura-Altamoura, a woman about whom little is actually known. The factual information includes the following; Eleni was born in the small island of Spetses. In her early twenties she travelled to Naples dressed as a man, and studied painting in the same guise. Later, and in love with fellow painter Saberio Altamura, she resumed the feminine dress. When their short-lived marriage ended, she returned to Athens with her children and eventually withdrew to Spetses. Galanaki imagines Eleni speaking from the ancestral home in Spetses, re-examining femininity, maternity, returning home and assigning meaning to one's life.

Bosteels sets the scene for the convergence of Foucault and Lacan when discussing the function of non-places in post-structuralist thought. He argues that non-places arise when we need to think 'the haphazard nature of an event without losing track of its structural overdetermination' (Bosteels 2003, p.120). In Foucault the non-place - for which the term 'heterotopia' is used as a free variant - is the place of articulation between continuity and rupture or history and novelty, a place from which one - Foucault included - can speak critically (2003, p.124). Further, it is the gap (non-place) in which the new 
and the unheard-of may arise (Bosteels 2003, p.123). In psychoanalysis, the non-place is closely associated with the experience of analysis as the site in which something new and as yet unrepresented but already structurally overdetermined may arise. For this claim, Bosteels draws on Miller who, faithful to Lacanian doctrine, dispenses with the conscious subject in favour of what awaits to emerge in language (Bosteels 2003, p.129).

For Žižek, what awaits to emerge in language is both the interpretation of a symptom and a fantasy, the subject's special mode of attachment to the socio-symbolic Other. Symptoms are to be interpreted, notes Žižek, fundamental fantasies are to be (re)constructed (Žižek 1997, p.36). Both, in my view, are necessary for gaining a better understanding of the exploration of the feminine and the maternal in heterotopic spaces. Žižek is interested in cases where the Other is seen as depriving the subject of a jouissance (enjoyment) rightfully belonging to her (Žižek 1997, p.33, 35). Liberation from such a false dependence comes when the subject finally shutters the myth of the Other as 'the one who pulls the strings' (Žižek 1992, p.40). Without the Other, notes Verhaeghe, one is left with a 'being' which is 'infinity as such' (2001, p.103).

Glynos and Stavrakakis employ the distinction between the ideological subject and the ethical subject to mark the difference between the two modes of engagement with the socio-symbolic Other: 'insofar as the subject's relation to social norms is mediated in a phallic mode, we understand this subject as an ideological subject; and insofar as the subject engages by means of a non-phallic enjoyment, we can qualify it, following Lacan, as an ethical subject' (2008, p. 265). Indeed, a feminist concern should be the subjective experience which eventually gives rise to the possibility of a non-phallic engagement and an ethical existence within the socio-symbolic domain. But for some women, I argue, the ethical starts elsewhere, in a heterotopic place. Thus, heterotopia/analysis is the locus of the speaking subject's liberation from her symptoms and the traversal of the fantasy, or the point at which one sheds the baggage of the unconscious in one symbolic gesture (Zupančič 2000, p.61). Speaking from the heterotopic-analytic place, a woman who gives a critical account of her life examines her own narrative constructions. This is not a matter of telling yet another story but of making sense of what lies outside the traditional phallic mode of being: admiration for the male, imitation, copying his manners and clothes, abiding by his desire or simply disavowing castration. It is also a chance of going beyond the $\mathrm{M}(\mathrm{O})$ ther as representative of the Paternal/Patriarchal order. 
Below I illustrate the re-examination of life in the maternal/heterotopic space. I present a selection of ways of being, symptoms and fantasies, that are indicative of gender discontent and ambivalence. I focus on their aggressive nature and note that they appear to 'erupt' - like overdetermined traumatic events - and disturb an 'unsuspecting' female subject.

All three women embark on the journey to self-discovery with a desire for a nostalgic break with contemporary time. Foucault notes that heterotopias are usually 'connected with temporal discontinuities (heterochronias)' (2000, p.182). Thus Marina longs for the childhood 'Magium' once located in the spiral core of a transparent marble. In Filthy Weather, the Frenchwoman's house is a relic of the seventies, complete with a full wardrobe, old newspaper clippings and expired tinned food. In Eleni or Nobody, the house in Spetses is isolated from the world. From there Eleni is free to denounce her maiden and marital surnames (Boukoura and Altamoura), and revert to using an old family surname (Krysini) which had been obsolete for generations (Michalopoulou, 1998, p.169). The confusion of names and roles extends to her relationship with her maid, an old woman who often tells her mistress what to do rather than taking orders from her. Further, Eleni now prefers living with the vivid memories of the dead, given to the peculiar temporality of their visits.

In The Magium, nostalgia chimes with the postmodern condition of homelessness (Chambers 1994) or, as Kristeva notes, with the impossibility to return from exile (1991, p.43). This meaningless 'return' seduces the woman but as it is a journey backwards in place and time, it can only produce repressed horrors rather than comfort. Marina remembers the advent of heterosexuality and the defensive splitting of the ego (Freud 1991 ) as a traumatic order given by a ferocious 'M(O)ther' which is the mouthpiece of the patriarchal status quo:

The 'Other' is an imaginary being... which first appeared to Marina one night as she was trying to talk to 'Herself' ... The 'Other' decreed that from then on she [Marina] would not be called 'Herself' but would be known by different names - according to the occasion; misleading names would dominate her days and works; she would, for instance, be known as Ariadne to her lover and appear in front of him dressed in a jumper whose yarn he could unravel in order for him to undress her (p.88).

In Filthy Weather, the heterotopic villa is where incompatible elements come together: maternal longing, sexual discontent and violence. Stranded due to an outbreak of 
bad weather, Victoria, her boyfriend and two other women embark on a sexual act which she finds bizarre rather than pleasurable. She visualises it like a surrealistic collage of incongruous body parts that do not amount to whole bodies. The fragmentation of bodies is succeeded by a desire for peace akin to a desire to return to the prelingusitic maternal chora. Victoria observes one of the women, Zoë, who lies self-absorbed by the fireplace. She thinks: 'her prelinguistic self had prevailed. I knew. I, too, was like that' (p.325). The lull is disrupted by an act of homicide. Startled by strange noises in the house, the four friends corner a 'creature' on the top floor from where it falls to its death from a window. The following morning they realise that it was an old man, the Frenchwoman's partner, who lived there as a recluse. Kristeva summarises the dizzying effects of not having dealt with the phallus properly: 'death breaks into the peace one thought one had taken in' (1987, p.81).

In all three novels, the heterotopic $\mathrm{M}(\mathrm{O})$ ther place emerges not as a safe haven from the problems of identity and gender, but as the only locus in which they must now be addressed. Adhering to the patriarchal (phallic) order, the woman merely repeats the internal dilemmas which gave rise to conflict in the first place. She struggles with the either/or of heterosexuality, of 'being' or 'having' the phallus and the maternal as either an enveloping womb (space) or a persecuting agent. My point is that it is the very incompatibility of these emplacements rather than their happy resolution that holds the key to the settlement of the maternal and the feminine.

When Marina reaches the Magium, ${ }^{3}$ she finds it to be an upside-down theatre in which an all-female cast performs, headed by a female lead-actor called Saskia. Mother is among them. She walks on stage, speaks a few platitudes and leaves. No enlightenment occurs. The name Saskia becomes more significant than the pursuit of the mother; it duplicates the name of a male psychotherapist whom Marina had once consulted in an effort to 'put her pieces back together' after the death of her mother. She has only contempt for him and his overrated expertise. Yet the homonymy between Saskia, the male subject of knowledge and power, and Saskia, the female/maternal actor, becomes Kolliakou's solutions to the problems of representation, signification and desire. It assigns all things paternal and maternal an equiprimordiality of origin (Shepherdson 1995) which preserves their distinctness but refuses to locate them in a hierarchy of (patriarchal) power. 
A similar route is chosen by Michalopoulou: when Victoria is found out to have stolen diaries and notebooks from the other holiday makers - only borrowed for inspiration, she claims - she heads for the Frenchwoman's house, where she makes it her mission to find out more about that mysterious woman's life. Eventually, she pieces her story together, including the curious homonymy of the Frenchwoman's name, 'Jeanne', with her partner's name, 'Jean'. Victoria buries her notebooks in the heterotopic beach and with them her desire to imitate her writer boyfriend. She only keeps a picture of Jeanne and Jean as a memento of the adventure.

Eleni settles her past with a reconciliation and a sacrifice. First, she reconciles herself with the once loathsome female sex: 'I was a coward three times over because I was afraid of the placidity of the ancient female world and tried to hurt it with my pencils and my brushes, with rationalisation and knowledge, with a seductive life dressed in men's clothes' (Galanaki, 1998, p.182).

Then, after finding herself too obsessed with her own ambitions, she gathers all her paintings in the yard and sets them on fire (1998, p.182). The sacrifice of the paintings annuls the past and leaves Eleni free from the baggage of the unconscious. It would not be exaggerated to say that Eleni becomes an inhabitant of heterotopia there and then; neither a man nor a woman, painter or mother by the standards of conventional signification, but an empty signifier (nobody) which sums up the suspension of problematic binary oppositions.

In this final section, I want to argue that the heterotopic maternal place may be a permanent critical site for women. My first observation concerns the tactics of choosing homonymy (Saskia and Saskia, Jeanne and Jean) over binary opposites. Homonymy, which evokes similarity, allows for a different order-ing (Hetherington 1997), for incompatible emplacements (such as mother as locus and agent, love and hatred, heterosexuality and homosexuality, omnipotence and weakness) to exist side by side. It does not constitute an attempt to evade the phallus or disavow castration, but brings to the fore a kind of non-place of classification which - to echo Foucault - challenges the dominant order of things.

The new ordering dispenses with the desire to go back to one's roots or origins, and concerns the present. For that reason, the return to the $\mathrm{M}(\mathrm{O})$ ther is always a 
disappointment or failure. Women are, to borrow Shepherdson's expression, like the genealogist who attempts to rewrite the past, 'producing a shift in the symbolic structure of the narrative that brought us to the point where we are now' $(1995, \mathrm{p} .5)$. Shepherdson draws a parallel with Freud at this point. Freud, he notes, has this shift and the emphasis on the present in mind when he discusses the symptom and its dissolution. He aims at altering the structure here and now rather than getting the patient to remember $(1995$, p.5). Echoing Freud, Žižek also assigns particular significance to the historical break effected in the present, 'the shift in the very grid which enables us to measure losses and gains' (1997, p.13). This reassessment is, in my view, central to the contemporary shift of women's attitudes. It is accomplished in and represented by a space in which the horrors of unresolved tensions turn into a place with-in which they ground their difference.

Resulting from both the traversal of fantasies and symptoms and the departure from conventional hierarchical order, this place has the potential to become a permanent ethical and universally valid locus for an ethical feminine subject. It inaugurates a critical attitude towards the world and oneself by means of a transgressive (Foucault) or 'traversarial' (Žižek) ordering. From a psychoanalytic perspective, this locus spells out a difficult task for women; in order to be able to speak critically, to be an ethical subject by always examining oneself critically as Foucault would suggest, one must always inhabit a non-place, the alternative to the phallic symbolic order, to imaginary identifications and even to the elusive Real. This place, which holds together the orders of the Symbolic, the Imaginary and the Real in their relative incompatibility, must operate like a sinthome (Evans 1996, p.189), the 'fourth order' which holds the other three together and allows one to live by providing 'a unique organisation of jouissance' (Evans 1996, p.189).

By grounding (ethical) femininity in the heterotopic realm, a new iconography emerges. It is best captured by Eleni the artist, who finally sums up her life in the following words: '[I could have spoken] not about everything, since 'everything' does not exist, but about the ripples I caused when I, the ephemeral stone, fell into the water' (1998:199, emphasis added). The ripples as continuously expanding concentric circles is a far more life-affirmative articulation of one's life than 'nobody', as well as a visual alternative to the homonymy preferred by the younger generation. All three chime with the infinity Verhaeghe associates with the traversal of the Other (2001, p.229) and contribute to the revision of what Cornell calls the traumatic heterosexual imaginary (2007 
p.229). Thus the non-place of heterotopia and analysis may become a paradoxical (non)birthplace for women, reverberating with the maternal in all its guises, but seeking neither to restore nor to abolish it. Alternatively, it can be imagined as a permanent critical point of passage (Hetherrington 1997) for existentially itinerant contemporary women.

\section{References}

Barr, M., 1992. Feminist fabulations, Space/Postmodern fictions. University of Iowa Press.

Bosteels, B., 2003. Nonplaces. An anecdoted topography of contemporary French theory. Diacritics, 33 (34), 117-39.

Brinkmann, S., 2009. Literature as qualitative inquiry: The novelist as Researcher. Qualitative Inquiry, 15(8), 1376-1394.

Chambers, I., 1994. Leaky habits and broken grammar. In G. Robertson et al (eds), Travellers tales: Narratives of home and displacement. Routledge.

Cornell, D., 2007. The shadow of heterosexuality. Hypatia vol 22(1), 229-242.

Durante, R., 2001. The dialectic of self and story: Reading and storytelling in contemporary American fiction. Routledge.

Evans, D., 1996. An introductory dictionary of Lacanian psychoanalysis. Brunner-Routledge.

Foucault, M., 2006. The order of things. Routledge.

Foucault, M., 2000. Different spaces. The essential works of M Foucault 1954-1984, vol 2. Penguin Press, 175-185.

Foucault, M., 1980. Power/Knowledge: Selected interviews and other writings 1972-1977. Pantheon Books.

Freud, S., 1991[1938]. Splitting the ego in the process of defence. Penguin Press.

Galanaki, R., 1998. Eleni i o kanenas [Eleni or nobody]. Agras.

Hetherington, K., 1997. The Badlands of modernity. Routledge.

Glynos, J. \& Stavrakakis, Y., 2008. Lacan and political subjectivity: Fantasy, and enjoyment in psychoanalysis and political theory. Subjectivity, 24, 256-274.

Kolliakou, D., 1999. To Magio (The Magium). Estia.

Kristeva, J., 1991. Strangers to ourselves. Cambridge University Press.

Kristeva, J., 1987. Tales of love. Columbia University Press.

Laurenston, D. \& Singewood A., 1971. The sociology of literature. McGibbon \& Kee.

Michalopoulou, A., 2001. Paliokeros (Filthy Weather). Kastaniotis.

Shepherdson, C., 1995. History and the real: Foucault with Lacan. Postmodern culture, 5 (2), 1-37.

Tamboukou, M. 2000. Of other spaces: Women's colleges at the turn of the nineteenth century in the UK. Gender, place and culture, 7 (3), 247-263.

Van Dyck, K., 1998. Kassandra and the censors: Greek poetry since 1967. Cornell University Press.

Verhaeghe, P., 2001. Beyond gender: From subject to drive. Other Press.

Voela, A., (forthcoming). Heterotopia revisited: Foucault and Lacan on feminine subjectivity. Subjectivity.

Žižek, S., 1997. The plague of fantasies. Verso press.

Angie Voela, Locating the Mother

Studies in the Maternal, 2 (1) 2010, www.mamsie.bbk.ac.uk 
Žižek, S., 1992 Enjoy your symptom: Jacques Lacan in Hollywood and out. Routledge.

Zupančič, A., 2000. Ethics of the real. Verso.

${ }^{1}$ Galanaki (b. 1947) lives in Patras, Greece. A poet and novelist with sound feminist credentials (Van Dyke 1998), she explores the fluidity of subjectivity and gender, the impossibility of belonging to any imaginary homeland, the heavy fate of femininity in the past and the dead-ends of masculinity in more recent times. Michalopoulou (b. 1966) and Kolliakou (b. 1968) belong to a younger generation brought up in politically stable and affluent times (see Mackridge and Yannakakis 2004), (this needs to be in the reference section) in a country aspiring to Western life style and values. Michalopoulou lives in Athens and has lived in Paris and Berlin. Her novels deal with experiences of sexuality, the subversion of the binary opposition of gender and a feminine becoming that usually involves breaking bonds and crossing boundaries. Kolliakou (b. 1968) is an academic and lives in Newcastle, UK. She has lived in Greece, Holland and Israel. Her novels explore an itinerant feminine existence and the experience of moving between cultures as well as between fantasy and reality.

${ }^{2}$ For a detailed discussion of this novel in terms of heterotopia and psychoanalysis see Voela, A. (forthcoming). Heterotopia Revisited: Foucault and Lacan on Feminine Subjectivity. Subjectivity.

${ }^{3}$ In the novel it is really Marina's sister and alter ego Anastasia that reaches the Magium. This detail does not however affect my argument.

Angie Voela, Locating the Mother

Studies in the Maternal, 2 (1) 2010, www.mamsie.bbk.ac.uk 